\title{
Leveraging mobile technology to reduce barriers to maternal, newborn and child health care: a contribution to the evidence base
}

\author{
Jean Christophe Fotso ${ }^{1, a}$ and Amy Tsuib \\ ${ }^{a}$ Concern Worldwide US, New York, USA \\ ${ }^{b}$ Bill \& Melinda Gates Institute for Population and Reproductive Health, \\ Johns Hopkins School of Public Health, Baltimore, USA
}

\section{Introduction}

Significant progress has been achieved worldwide in recent decades to improve the health of women and reduce the number of children who die before their fifth birthday (UN 2010). The efforts of governments in low and middle income countries (LMICs) and their development and funding partners have coalesced around the twin Millennium Development Goals (MDGs) 4 and 5 , and steadily contributed to breaking the vicious cycle of poverty and poor maternal, newborn and child health $(\mathrm{MNCH})$, even in some of the poorest countries in the world (WHO \& UNICEF 20I2). In 20I3, the world's maternal mortality ratio (MMR) was estimated at 210 deaths per 100,000 live births, down from 380 in 1990. Despite this progress, more than 275,000 women worldwide die annually from preventable complications related to pregnancy and childbirth. Most of these deaths occur in sub-Saharan Africa (62\%) and Southern Asia (24\%) (UN 20I4). Another major development related to maternal health has been the gradual increase in the use of contraception in LMICs, largely as a result of improved access to safe, affordable and effective methods. In subSaharan Africa, the contraceptive prevalence rate among married women doubled between 1990 and 2012 from $13 \%$ to $26 \%$, yet unmet need for family planning remains high, standing currently at around $25 \%$ (WHO and UNICEF 2012).

On the newborn and child health front, the achievements have been remarkable and the prospects brighter since the mid-2000s. Globally, the underfive mortality rate almost halved between 1990 and 2012, from 90 to 48 deaths per thousand live births, and correspondingly, the number of under-five deaths dropped by nearly 6 million (UNICEF 20I3). With the exception of sub-Saharan Africa and Oceania, all regions recorded a steep drop in their under-five mortality rates (UN 20I4). The overall sluggish decline in sub-Saharan Africa notwithstanding, a number of countries in the region like

\footnotetext{
${ }^{1}$ Corresponding author

Concern Worldwide US, 355 Lexington Avenue, 19th floor; New York NY 10017, USA.

Tel: +1-212-557-8000; Fax: +1-212-557-8004

Email: jean-christophe.fotso@concern.net
} 
Malawi (the main focus of this Supplement) have already met or are on track to meeting the target for MDG 4 (UNICEF 2013). While the pace of progress is remarkable, around 6.6 million children continue to die each year before their fifth birthday of causes that can be addressed with known interventions (UN 20I4).

\section{Accelerating the pace of progress towards MDGs 4 \& 5 by removing barriers to access to care}

Not only is sub-Saharan Africa the region with the highest child mortality rate in the world, it is also the only region where the number of live births and the under-five population are expected to rise substantially over the next two decades (UN 20I4). Accelerating the pace towards attainment of the health-related MDGs and soon the Sustainable Development Goals (SDGs) should feature on top of the agenda of health and development. A number of demand- and supply-side barriers challenge the improvement of maternal and child health and survival (Welsh et al., 2006; Shelton et al., 1992).

Geographic or physical access barriers, measured by distance to appropriately equipped and staffed health facilities often delay or inhibit care seeking, especially among poor families living in difficult to reach settings (Blanford et al., 20I2; Silal et al., 20I2). Direct financial barriers, such as the affordability of services have been shown to hinder women's access to health care, particularly when pregnancy, delivery complications or acute child illnesses require specially trained staff. Families and parents may also have to purchase medical supplies and equipment that are not in stock at the clinics. Studies show that medical administrative barriers arise too when only certain types of health facilities or staff are authorized or certified to provide life-saving services (Dawson et al., 20l4), such as managing difficult labor or treating post-abortion complications.

Psychosocial barriers are often a pervasive source of challenges to appropriate client care. Prior to, or at the time of need, clients may lack information or knowledge to recognize the importance of seeking care or may be reluctant to seek care at specific health facilities. Socio-cultural beliefs and norms may also prevent pregnant women and mothers with sick children from obtaining timely care or using medications properly (Mushi et al., 2007). Indeed myths and misconceptions about medications or treatments, such as contraceptives, insecticide-treated bednets, or vaccinations, abound in many settings (Ojakaa et al., 20II), particularly low-income ones, which have some of the most adverse morbidity and mortality levels. Evidently, the importance of neutralizing and eradicating misinformation is as critical as preventing adverse health outcomes.

The Innovations for Maternal, Newborn \& Child Health (Innovations), an initiative of Concern Worldwide US, seeks to develop and test innovative interventions and strategies to address common barriers that prevent essential health services from reaching women and children. One of its projects upon which most papers in this Supplement are based, aimed at harnessing the opportunities offered by the rapidly expanding field of mobile health (mHealth) to alleviate some of the 
barriers that hinder the uptake of health services and healthy behaviors.

\section{Harnessing the potentials of mHealth}

mHealth refers to health practice that is supported by the use of mobile technologies, particularly devices such as smartphones and tablets, but also geospatial or environment-sensing and body monitoring equipment that increase access to health information, diagnostics, treatment and care (Mehl and Labrique 2014; mHealth Alliance. 20I2; Noordam et al. 20 II). Increasingly smartphones, which are usually equipped with a camera and global positioning system (GPS) locator, are used to transmit data, visual images and location to enable analysts to evaluate the severity of symptoms, location of infected cases, and behavioral response patterns (Labrique et al., 2013).

$\mathrm{mHealth}$ applications fall into five broad groups: I) information and education to share information about important health issues (Gurman et al., 20I2); 2) immediate information access, such as through a dedicated hotline or specialist consultation; 3) clinical support to health workers, connecting them to information databases, such as those about drugs or diseases, specialist staff at referral facilities, or training materials (Lemay et al., 20I2) ; 4) remotely assisting patients with self-monitoring (Castaño et al., 2013; Horvath et al., 20I2), such as blood sugar levels for diabetes or adherence to treatment therapies; and 5) recordkeeping and surveillance of health epidemics and outbreaks of new infections, health behaviors and practices, and epidemiologic patterns of infection transmission (Tomlinson et al., 2009).
mHealth and other ICTs offer substantial promise in reducing the geographic/physical , financial, administrative and psychosocial barriers to health care mentioned above (Labrique et al., 20l3). Short message service (SMS) transmission of information through mobile phones has been used frequently to remind patients of daily medication needs, pregnant women of antenatal care or mothers of immunization visits, and other individuals with defined need who otherwise may not gain the knowledge needed to seek appropriate care (Crawford et al 2014; Goodall et al., 2010). They can socially network individuals with need to others who have experienced illness and used the information or acquired knowledge for care and treatment. This can be effective in reducing psychosocial barriers to certain health or medical treatments. Applications that promote shared transportation to town or city centers, or enable more timely connections to available vehicles, can also reduce physical access barriers (Case, Morrison \& Vuylsteke, 20I2). This can be particularly important for pregnant women in labor or ill children with rapidly deteriorating health conditions. Other applications, such as Google Earth, which can display the surrounding ecology and terrain, road networks and service infrastructure, help analysts estimate difficulty of travel to eligible points of care (Neelkamal et al., 2013).

Health providers located in remote areas with mobile connectivity can also obtain peer advice and guidance on treating ill children or managing women in advanced stages of labor or with obstetric emergencies. Mobile applications for health providers, combined with audio input, can replace 
the foundation sessions of traditional training programs and also be combined with counseling and advice through peer networks. Simple actions such as photographs of displays of service charges, commodity inventories, patient rights or conditions of surgical theatres and clinic care and services can be revealing to health system administrators charged with quality assurance. mHealth video technology or multimedia applications readily facilitate transparency in patient care, commodity flows through supply chains, and provider-client interactions (Choi and Kim, 20l4).

Overall, while its applications are still nascent and sporadic in coverage, the potential of mHealth to improve the supply of $\mathrm{MNCH}$ care and reduce the costs of meeting clients' demand is substantial, as the cost of mobile phones declines, telecommunications connectivity expands and bandwidths are strengthened.

\section{About the Innovations for MNCH}

The Innovations for Maternal, Newborn and Child Health Initiative started in 2010 with in-depth research to identify the most serious and widespread barriers to delivery of health services for mothers and children in specific contexts, and then generated ideas for interventions to address those barriers. This process, referred to as ideation phase, engaged communities in low-resource settings, tapped unheard or unconventional voices at both global and country levels, and honed the ideas through cross-disciplinary inputs from experts from many different fields not usually involved in public health program design. It ultimately generated four
Phase I projects which were designed and implemented between 2009 and 20I3. These include the information and communications technology (ICT) for $\mathrm{MNCH}$ in Malawi, which is the focus of this Supplement (See Annex I). Drawing from the initial ideation pool, the learnings from Phase I, and additional formative research in selected countries, five other projects referred to as Phase II, were designed and launched in 2013/2014 (see Annex 2).

The initiative's research, monitoring and evaluation (RME) plan seeks to determine the effectiveness of the intervention in overcoming the identified barriers to $\mathrm{MNCH}$ services, and to explore how and why these interventions achieved their results. Data sources include routine monitoring, baseline and endline assessments and process documentation. Also important to the initiative's overall strategy is the experimentation and learning related to the application of human-centered design in $\mathrm{MNCH}$ in developing country settings (Brown and Wyatt 20l0). Equally central to the Initiative is the incorporation of human rights principles into the project and research designs. Drawing from major UN frameworks and with inputs from UNICEF and external experts, Innovations developed its human rights framework around four principles: right to health, nondiscrimination, participation, and accountability (Gruskin et al. 2010, UNICEF 20I2).

\section{Overview of the Supplement}

The overall aim of this Special Issue is to contribute to the discourse on the booming field of ICT for health, and to contribute to the evidence base on the effectiveness of $\mathrm{mHealth}$ interventions 
to improve $\mathrm{MNCH}$ outcomes. The Supplement is comprised of seven core papers, four of which draw on evaluation data from the Innovations project in Malawi called ICT for MNCH or CCPF (Chipatala Cha Pa Foni, or health center by phone in the local language).

The first paper by Fotso et al. investigates the impact of the mHealth intervention on aggregate home-based and facility-based care for $\mathrm{MNCH}$, comparing the intention-to-treat (ITT) and the treatment on the treated (TOT) estimates, and discussing the implications for future evaluations. The paper concludes that rigorous evaluation designs can be successfully applied to mHealth projects, helping to understand what works and what does not. In the second paper, Larsen-Cooper and colleagues examine the effect of two strategies on access to and utilization of the mHealth service amongst people without personal phones: community volunteers phones, and interactive voice response system. Noting that less than $35 \%$ of users of the proposed services had access to a personal phone, the authors suggest that further investigations should be carried out to better understand the resources and efforts needed to sustain access strategies in the context of low phone penetration.

The two following papers assess the impact of the CCPF intervention on specific $\mathrm{MNCH}$ outcomes. HigginsSteele et al.'s paper details the TOT effects of the mHealth intervention on the individual and aggregate variables for facility-based care for mothers and children. It identifies the outcomes on which the intervention had a positive impact, those on which it had a negative effect, and those for which there was no detectable effect. The paper by Fotso et al. on the other hand, has a focus on child health. Key to the analyses is the investigation of the extent to which uptake of home-based care resulted in lessened pressure on health facilities for conditions that can be handled at the household level. The quantitative and qualitative findings suggest that the intervention helped women avoid unnecessary trips to the health facility for care that could be provided at home.

The fifth paper in the series is a global review which broadens the scope of the Supplement one step further. Authored by Vesel et al., it explores the opportunities and challenges of the application of mHealth to improve service delivery and health outcomes. Among other points, the paper argues that the benefits of mHealth can only be realized if the associated risks are minimized and the barriers are purposefully overcome, and supports the view that government stewardship and leadership is crucial to overcome these barriers and scaling up mHealth interventions. The sixth paper by Zimmerman et al. shifts the focus from mHealth interventions to the integration of mobile technology into survey implementation. It concludes that integration of mobile technology with survey implementation holds significant promise for rapid, high quality data collection that can generate timely and relevant information.

The seventh substantive paper by Smith-Estelle et al. brings to the fore the incorporation of human rights principles into health programming. The paper states that while the application of human rights norms at the national policy level is largely codified, the application to public health programs is still in its infancy. The authors identify 
four key human rights principles and discuss their application to the CCPF project. Finally, the concluding commentary by Mechael summarizes the insights from the seven papers. The author notes that the collection helps to fill in some critical gaps in the evidence base, and elevates the debate to the critical issue of sustainability and scale. She concludes that the move from impact to scale and sustainability in the field of mHealth for $\mathrm{MNCH}$ commands a range of approaches from health outcomes research to stakeholder and policy mapping and analysis to human rights and equity.

We wish you a happy reading!

\section{Acknowledgements}

Innovations for Maternal, Newborn \& Child Health (Innovations) is an initiative of Concern Worldwide U.S. funded through a multi-year grant from the Bill \& Melinda Gates Foundation. The Government of Norway and the United Nations Foundation also supported the Malawi mHealth project (CCPF) through the Innovation Working Group Catalytic mHealth Grants program as part of the UN Secretary General's Every Women Every Child strategy. UNICEF is Innovations' global partner. The scope of relationships between Innovations and UNICEF is captured in Memorandum of Understanding under which a staff member of Concern Worldwide US serves as the focal point within UNICEF to promote joint work and facilitate knowledge-sharing between the two organizations. Options UK was the global research partner for Phase I, and John Snow Inc (JSI) is the global research partner for Phase II.
We would like to give special thanks to the Reproductive Health Unit and its Director, Mrs. Fannie Kachale, and the Balaka District Health Office for their support of the CCPF project. Our special thanks to Professor Susan Watkins of University of Pennsylvania and Dr. Amanda Robinson of Ohio State University for their leadership of the evaluation of the CCPF project. We thank Dr. Zacharie Tsala of University Ottawa, Canada for translating to French the abstracts of the papers in this Supplement. We also thank Ms. Victoria Steven of Concern Worldwide US for copy editing this document.

We would like to thank Prof. Clifford Odimegwu, Editor of the African Population Studies journal and Head of the Demography \& Population Studies Programme at the University of the Witwatersrand, Johannesburg for his support during the review process. Lastly, we are grateful to the anonymous reviewers.

\section{Authors' Contributions}

JCF and AT both led the design and writing of the paper.

\section{References}

Blanford, J., Kumar, S., Luo, W., and MacEachren, A. 2012. "It's a long, long walk: Accessibility to hospitals, maternity and integrated health centers in Niger." International Journal of Health Geographics I I:24.

Brown, T., and Wyatt, J. 2010. "Design Thinking for Social Innovation". Stanford Social Innovation Review (Winter 20I0): 3I-35.

Case, T., Morrison, C., and Vuylsteke, A. 2012. "The clinical application of mobile technology to disaster 
medicine." Prehospital and Disaster Medicine 27(6): 473-280.

Castaño, P., Stockwell, M., and Malbon, K. 2013. "Using digital technologies to improve treatment adherence." Clinical Obstetrics and Gynecology 56(3): 434-445.

Choi, H., and Kim, J. 2014. "Effectiveness of telemedicine: Videoconferencing for low-income elderly with hypertension." Telemedicine and e-Health 20 (12): II56-II64.

Crawford, J., Larsen-Cooper, E., Jezman, Z., Cunningham S.C., and Bancroft, E. 20I4. "SMS versus voice messaging to deliver $\mathrm{MNCH}$ communication in rural Malawi: assessment of delivery success and user experience." Global Health: Science \& Practice 2(I):35-46.

Dawson, A., Buchan, J., Duffield, C., Homer, C. and Wijewardena, K. 2013. "Task shifting and sharing in maternal and reproductive health in low-income countries: A narrative synthesis of current evidence". Health Policy and Planning 29: 396408.

Goodall, K., Ward, P., and Newman, L. 2010. "Use of information and communication technology to provide health information: What do older migrants know and do they need to know?" Quality in Primary Care 18: 27-32.

Gruskin, S., Bogecho, D. and Ferguson, L. 20I0. "Rights-based approaches to health policies and program: Articulations, ambiguities, and assessment". Journal of Public Health Policy 3I (2): I29-I 45

Gurman, T., Rubin, S., and Roess, A. 2012. "Effectiveness of mHealth behavior change communication interventions in developing countries:
A systematic review of the literature". Journal of Health Communications 17: 82-104.

Labrique, A., Vasudevan, L., Kochi, E., Fabricant, R., and Mehl, G. 2013. "mHealth innovations as health system strengthening tools: 12 common applications and a visual framework." Global Health: Science and Practice I(2): 160-7I.

Lemay, N.V., Sullivan, T., Jumbe, B., Perry, C.P. 2012. "Reaching remote health workers in Malawi: Baseline assessment of a pilot mHealth intervention." Journal of Health Communication 17(Suppl): I05-II7.

Mehl, G. and Labrique, A. 2014. "Prioritizing integrated mHealth strategies for universal health coverage". Science 345: I284- 1287.

mHealth Alliance. 20I2. "Leveraging Mobile Technologies to Promote Maternal \& Newborn Health: The Current Landscape \& Opportunities for Advancement in Low-Resource Settings." Washington DC.

Mushi, D., Mpembeni, R., and Jahn, A. 2007. "Knowledge about safe motherhood and HIV/AIDS among school pupils in a rural area in Tanzania." BMC Pregnancy and Childbirth 7:5.

Noordam, A.C., Kuepper, B.M., Stekelenburg, J., Milen, A. 20II. "Improvement of maternal health services through the use of mobile phones." Tropical Medicine \& International Health 16(5):622-626.

Ojakaa, D., Yamo, E., Collymore, Y., BaNguz, A., and Bingham, A. 2011. "Perceptions of malaria and vaccines in Kenya". Human Vaccines 7(10): 1096-1099.

Shelton, J., Angle, M., and Jacobstein, R. 1992. "Medical barriers to access to 
family planning". The Lancet 340 (883 I): I334-5.

Silal, S., Loveday, P., Harris, B., Birch, S., and Mclntyre, D. 2012. "Exploring inequalities in access to and use of maternal health services in South Africa". BMC Health Services Research 12: 120.

Neelkamal, S., Soares, S., Johnson, A., and Patidar, N. 20I3. "Geomapping telehealth access to developmentalbehavioral pediatrics." Telemedicine and e-Health 19(8): 585-590.

Tomlinson, M., Solomon, W., Singh, Y., Doherty, T., Chopra, M., ljumba, P., Tsai, A., and Jackson, D. 2009. "The use of mobile phones as a data collection tool: A report from a household survey in South Africa." BMC Medical Informatics and Decision Making 9:5I.

UN (United Nations). 2010. Global Strategy for Women's and Children's Health. United Nations, New York, 2010.
UN (United Nations). 20I4. The Millennium Development Goals Report 2013. United Nations, New York, 2014.

UNICEF. 2012. Global Evaluation of the Application of a Human Rights Based Approach to UNICEF Programming. UNICEF, New York, 2012

UNICEF. 2013. Committing to Child Survival: A Promise Renewed Progress Report 2013. UNICEF, New York, 2013.

Welsh, M., Stanback, J., and Shelton, J. 2006. "Access to modern contraception". Best Practice \& Research Clinical Obstetrics and Gynecology 20 (3), 323-338.

WHO (World Health Organization) \& UNICEF. 2012. Countdown to 20I5: Maternal, Newborn and Child Survival - Building a Future for Women and Children. The 2012 Report. Washington DC, WHO and UNICEF. 


\section{Annex I List of Innovations for MNCH's Phase I (completed) projects}

\begin{tabular}{|l|l|}
\hline \multicolumn{1}{|c|}{$\begin{array}{c}\text { Project and country of } \\
\text { implementation }\end{array}$} & \multicolumn{1}{c|}{ Overview } \\
\hline ICT for MNCH, Malawi & $\begin{array}{l}\text { Using information and communications technologies } \\
\text { to connect pregnant women, caretakers and } \\
\text { children to health workers, thereby giving them } \\
\text { immediate access to personalized health advice, tips } \\
\text { and reminders via individual and community phones. }\end{array}$ \\
\hline $\begin{array}{l}\text { Male Health Activists, State of } \\
\text { Odisha, India }\end{array}$ & $\begin{array}{l}\text { Building on existing networks of female community } \\
\text { health workers by adding a cadre of Male Health } \\
\text { Activists who promote the importance and benefit } \\
\text { of MNCH services among male household decision- } \\
\text { makers. }\end{array}$ \\
\hline $\begin{array}{l}\text { Helping Health Workers Sierra Leone } \\
\text { Cope, Worke }\end{array}$ & $\begin{array}{l}\text { Providing access to group and individual counseling } \\
\text { services for health workers to cope with the stress } \\
\text { and pressures of their work as well as providing } \\
\text { training sessions for these health workers on stress } \\
\text { management, self-care and client care. }\end{array}$ \\
\hline Quality Circles, Sierra Leone & $\begin{array}{l}\text { Supporting health workers and traditional birth } \\
\text { attendants to develop peer learning, peer support } \\
\text { and joint problem solving skills to empower them to } \\
\text { be more effective in their jobs and resolve gaps and } \\
\text { failures in the health system. }\end{array}$ \\
\hline
\end{tabular}




\section{Annex 2 List of Innovations for MNCH's Phase II (ongoing) projects}

\begin{tabular}{|l|l|}
\hline $\begin{array}{c}\text { Project and country of } \\
\text { implementation }\end{array}$ & \multicolumn{1}{|c|}{ Overview } \\
\hline $\begin{array}{l}\text { Essential Newborn } \\
\text { Care Corps (ENCC), } \\
\text { Sierra Leone }\end{array}$ & $\begin{array}{l}\text { Rebranding traditional birth attendants as Maternal } \\
\text { Newborn Health Promoters who provide health advice } \\
\text { and referrals to the health facility for pregnant women and } \\
\text { newborns during home visits while selling health-related } \\
\text { products }\end{array}$ \\
\hline $\begin{array}{l}\text { Care Community Hub } \\
(\mathrm{CCH}), \text { Ghana }\end{array}$ & $\begin{array}{l}\text { Improving motivation and job satisfaction among frontline } \\
\text { health workers through a mobile "app" which offers } \\
\text { opportunities for professional development and reduces } \\
\text { the sense of social isolation among health workers posted } \\
\text { in remote areas. }\end{array}$ \\
\hline $\begin{array}{l}\text { Community Benefits } \\
\text { Health (CBH), Ghana }\end{array}$ & $\begin{array}{l}\text { Creatively using non-monetary incentives to cultivate } \\
\text { communities' investment and commitment to supporting } \\
\text { and improving maternal and child health. }\end{array}$ \\
\hline $\begin{array}{l}\text { Maker Movement for } \\
\text { MNCH (Maker), Kenya }\end{array}$ & $\begin{array}{l}\text { Creating a hub that links local makers, biomedical } \\
\text { engineers and MNCH practitioners to design, prototype } \\
\text { and test low-cost, high- quality, open-source and locally } \\
\text { produced essential medical equipment, devices and spare } \\
\text { parts. }\end{array}$ \\
\hline $\begin{array}{l}\text { Mobile Urgent } \\
\text { Maternity } \\
\text { (MUM), Kenya }\end{array}$ & $\begin{array}{l}\text { Using computer modeling to determine ideal locations of } \\
\text { ambulances and static emergency obstetric and neonatal } \\
\text { care clinics, and to create optimal routes for mobile clinics. }\end{array}$ \\
\hline
\end{tabular}

